\title{
Cámaras de aireación como sistema de control de la humedad de capilaridad en edificios históricos. Análisis de funcionamiento
}

\author{
Ventilated air cavities for the control of rising damp in historical buildings. \\ Functional analysis
}

$\underline{\text { Ma T. Gil Muñoz }}^{(*)}$, F. Lasheras Merino ${ }^{(*)}$

RESUMEN

En este estudio se aborda el comportamiento de las cámaras de aireación y su grado de eficacia como sistema de control de la humedad de capilaridad y los daños patológicos asociados en los muros o cimentación de los edificios históricos. Se ha establecido una metodología de experimentación in situ, haciendo uso de la monitorización. El conocimiento del clima local, el entorno del edificio, las características constructivas del mismo y el tipo de cimentación constituyen los condicionantes previos a la monitorización. La medición de distintos parámetros conforme a un plan de mediciones, el desarrollo de herramientas gráficas para el estudio y la elaboración de datos estadísticos han permitido aproximarse al objetivo marcado. La construcción de este sistema no siempre ha ido acompañado de un diagnóstico riguroso que justifique la intervención. Los resultados del estudio indican que esta situación ha influido en las estrategias de diseño y dimensionado de las cámaras de aireación, limitando en muchos casos la eficacia de las mismas.

Palabras clave: Cámara de aireación, humedad en muros, monitorización, evaporímetro Piché, tasa de evaporación.

\section{ABSTRACT}

This study analyzes the behavior of ventilated air cavities and their level of efficiency when used for the control of rising damp and the associated pathological damage in walls and foundations of historical buildings. The methodology is based on experiments on-site and monitoring. Knowledge of local climate conditions, the surroundings of the building, its construction features and the type of foundation constitute the preliminary conditions for the monitoring. In order to reach the goal we have measured several parameters according to a plan, developed graphical tools for the study, and prepared statistical data. The building of this system has not always been accompanied by a thorough assessment that would justify the intervention. The results show how this situation has affected the design strategies and sizing of the ventilated air cavities, limiting in many cases their efficiency.

Keywords: Ventilated air cavities, moisture in walls, monitoring, Piché atmometer, rate evaporation.

(*) Universidad Politécnica de Madrid (UPM) - Escuela Técnica Superior de Arquitectura (ETSAM) - Grupo de Investigación Análisis e Intervención en el Patrimonio Arquitectónico (AIPA)

Persona de contacto/Corresponding author: m.teresa.gil@gmail.com (M $\mathrm{M}^{\mathrm{a}} \mathrm{T}$. Gil Muñoz)

ORCID: http://orcid.org/oooo-0003-3674-2711 (Mª T. Gil Muñoz); http://orcid.org/oooo-0oo2-1252-5360

(F. Lasheras)

Cómo citar este artículo/Citation: Gil Muñoz, Ma T.; Lasheras, F. (2017). Cámaras de aireación como sistema de control de la humedad de capilaridad en edificios históricos. Análisis de funcionamiento. Informes de la Construcción, 69(548): e233, doi: http://dx.doi.org/10.3989/id.55476.

Copyright: (C) 2017 CSIC. Licencia / License: Salvo indicación contraria, todos los contenidos de la edición electrónica de Informes de la Construcción se distribuyen bajo una licencia de uso y distribución Creative Commons Attribution License (CC BY) Spain 3.o. 


\section{INTRODUCCIÓN}

Las cámaras de aireación son sistemas pasivos de control de la humedad capilar que afecta a los muros de los edificios. Según el tipo de humedad se pueden adoptar distintos sistemas constructivos a nivel formal y funcional. Para paliar la humedad de subsuelo, las cámaras suelen ser de recorrido longitudinal y adosadas a la base de los muros o cimentación de los edificios históricos. En algunos casos, su construcción es primigenia o bien se trata de intervenciones arquitectónicas más o menos recientes en el tiempo. Las cámaras de aireación objeto de estudio se construyen con la intención de paliar los procesos patológicos a que están sometidos los muros por efecto de la humedad de capilaridad, pero el origen del agua es diverso. Conocer este aspecto y lo que conlleva la presencia del agua parece fundamental para definir la solución constructiva idónea para estas cámaras.

El trabajo de campo y la documentación del estado del arte a través de los distintos agentes participantes en el proceso de diseño, dimensionado y construcción de las cámaras, así como mediante la consulta en archivos de los proyectos y memorias finales de obra, nos permiten observar que pocas veces hay un diagnóstico que argumente objetivamente la ejecución de este sistema. Diagnosticado el problema y entendiendo que la cámara de aireación es el sistema que puede paliar la problemática del muro, no existen unas pautas que guíen el diseño y dimensionado de esta solución. Y ejecutado este sistema, es infrecuente el seguimiento para testar el funcionamiento y la mejora que a priori supone la cámara de aireación en el edificio.

En este trabajo, se parte del estudio in situ de distintos casos ejecutados en la zona centro de la península. El estudio consiste en evaluar su dinámica de funcionamiento, analizando distintos parámetros físicos medidos in situ en distintos periodos estacionales. Esto nos permite aventurar el grado de eficacia de cada caso según las condiciones específicas de contorno.

\section{ESTADO DEL ARTE}

Existe una amplia bibliografía sobre la problemática de los muros sometidos a humedad de capilaridad y los posibles sistemas que la dan respuesta. Autores como Massari (1) o Salemi (2), y López Collado (3), Ortega Andrade (4) y González Fraile (5) en el ámbito nacional, describen las cámaras de aireación, pero ninguno de ellos ha demostrado su efectividad para control de la humedad de capilaridad, ni ha dado criterios técnicos para su construcción y dimensionado. Otra línea de trabajo es la que estudia los sistemas mecánicos de ventilación de las cámaras como es el caso de Freitas (6). También hay normas para determinar el comportamiento de los distintos parámetros físicos de los materiales en laboratorio, difíciles de aplicar in situ por las condiciones del ambiente y el equipo científico requerido de preparación de las muestras y ensayo.

En los últimos ochenta años este tipo de cámaras se ha ejecutado con cierta profusión en las intervenciones arquitectónicas de los edificios históricos en la península ibérica. En este estudio, se ha constatado que la mayor parte de las veces estas intervenciones no han estado precedidas por un diagnóstico que justifique la adopción de este sistema como solución a la problemática de la humedad de subsuelo. También se ha comprobado que este sistema, una vez ejecutado, no ha estado sometido a un seguimiento o un mantenimiento que certifiquen la mejora que ha supuesto en la conservación del muro o disminución del proceso patológico.

En el ámbito de la construcción se utilizan distintos términos para referirse a este sistema. Se denomina cámara de aire, cámara de aire ventilada, cámara de ventilación, cámara bufa, etc. En este estudio se ha optado por el de «cámara de aireación». Según Paricio (7) la aireación conlleva una velocidad del aire menor que la ventilación -los flujos de aire medidos en las cámaras son muy pequeños-. Normalmente la «cámara de aireación» tiene una disposición horizontal, perimetral a la base de los muros en su cara interior y/o exterior, bajo la cota de solado. La «cámara bufa» se relaciona en mayor medida con un trasdosado en la cara interior del muro, en disposición vertical, con respiraderos, sobre la cota de solado. En cualquier caso se trata de sistemas pasivos que a priori tienen como finalidad propiciar la evaporación del muro a través del flujo de aire en la cámara. Incluso según el sistema constructivo que lleve aparejado se denomina: bóveda de ventilación, solera ventilada, forjado sanitario, etc.

Pero la cámara de aireación puede incorporar distintas funciones. Estas son: drenaje de la escorrentía superficial del terreno próximo, conducción de aportes de agua fortuitos procedentes de las redes urbanas (abastecimiento, saneamiento, riego), conducción de pluviales de cubierta y del entorno cercano, y ventilación de la cámara con la consiguiente evaporación del muro de cimentación o suelo de la cámara, siendo esta la función principal. La respuesta a las distintas funciones se resuelve de manera separada o conjunta. También se han de tener en consideración los distintos aspectos formales: sección y dimensión de la cámara, disposición, orientación y tamaño de los huecos de ventilación, permeabilidad de los materiales y ejecución, disposición de chimeneas, etc.

\section{OBJETIVOS}

Se plantean los siguientes objetivos:

Monitorizar in situ distintas cámaras de aireación, ejecutadas en edificios históricos de la zona centro de la península, en distintos periodos estacionales.

Analizar el funcionamiento de las cámaras de aireación según condiciones de contorno, características formales, características funcionales y parámetros físicos medidos (temperatura, humedad, velocidad del aire y evaporación).

Valorar cualitativamente la eficacia de funcionamiento de las cámaras de aireación.

\section{METODOLOGÍA}

Se han tomado como referencia distintos estudios científicos en donde se describe la metodología de diagnóstico de la humedad en muros y su evaporación, ya sea in situ, como son los estudios de García Morales (8) y Kurtniski (9), o a nivel experimental en laboratorio, como es el trabajo llevado a cabo por Sandrolini (10).

La metodología de trabajo del presente estudio se ha estructurado en los siguientes puntos: relación de condicionantes, 
selección de casos de estudio, instrumentación y monitorización in situ.

Los condicionantes que se han considerado fundamentales han sido: conocimiento del clima local, descripción de las particularidades del entorno, aproximación al tipo de suelo y posición del nivel freático (NF), estudio de las características constructivas de los edificios que atañen a la dinámica de funcionamiento de las cámaras de aireación y aproximación a las características constructivas de las cámaras de aireación a nivel formal y funcional.

Previo a la selección de los casos de estudio más representativos, se utilizó una cámara de drenaje-aireación como piloto, en el convento de Santa Cruz la Real de Segovia, cuya cámara está ubicada en la cara exterior del muro sur de la iglesia (11). Los casos de estudio seleccionados en la zona centro de la península son cámaras lineales ventiladas, perimetrales a la base del muro o cimentación, situadas bajo el solado. Estas son: la cámara del atrio de la catedral de Zamora y las cámaras de las iglesias de San Salvador de los Caballeros y San Lorenzo el Real de Toro (Zamora). Todos los casos de estudio se encuentran por encima del nivel freático.

Se han llevado a cabo distintas instrumentaciones y monitorizaciones in situ en los casos de estudio. Los aspectos que se han contemplado son: relación de variables objeto de estudio, tipología de equipos y sondas de medición de los distintos parámetros, elaboración de un plan de mediciones aplicado de manera específica a cada caso, desarrollo de herramientas gráficas para el estudio y elaboración de datos estadísticos según los distintos parámetros.

Las variables objeto de estudio han sido: temperatura, humedad, velocidad y evaporación del aire, así como la presión barométrica.

Los equipos empleados para la medición de las distintas variables han sido: varios termohigrómetros, varios evaporímetros (evaporímetros de Piché y recipientes a modo de tanques evaporimétricos) y un anemómetro. Los termohigrómetros (PCE-HT 71 y MSR 145) se han calibrado por comparación en un observatorio de la Agencia Estatal de Meteorología (AEMet). El evaporímetro Piché utilizado es el modelo que usa la AEMet. El anemómetro (TESTO 435-2) está convenientemente calibrado según certificado de la casa comercial. El estudio se ha completado con la información del clima local suministrada por la AEMet en función de la ubicación de los distintos edificios (temperatura, humedad, velocidad y evaporación del aire y presión barométrica).

La instrumentación ha precedido a la monitorización, como medida primera de aproximación al comportamiento higrotérmico de las cámaras y los muros. Para la monitorización se han establecido periodos de observación de 9 días, en situaciones de anticiclón y borrasca, característicos de las estaciones meteorológicas de verano (periodo seco) y otoño o primavera (periodo de lluvias) respectivamente en la península ibérica. Se han realizado mediciones del ambiente de la cámara y del edificio (situando el sensor en el punto medio de la sección de la cámara y en un lugar representativo del ambiente interior del edificio), así como del muro en contacto con la cámara de aire y en contacto con el ambiente interior del edificio. De este modo se han caracterizado el comportamiento del ambiente interior del edificio, del ambiente interior de la cámara y del muro en contacto con ambos ambientes (figura 1), teniendo siempre como referencia los datos del clima local.

En el análisis de los datos medidos se ha hecho uso de distintos recursos gráficos: gráficos de curvas, gráficos de caja y bigotes, y diagramas psicrométricos. En los gráficos de curvas se representan valores medidos (temperatura y humedad cada hora), valores promedio (temperatura y humedad en 24 horas) o valores acumulados (evaporación en 24 horas). En los gráficos de caja y bigote se representan 5 datos de una misma variable: en la caja quedan representados la mitad de los datos, desde el cuartil inferior hasta el cuartil superior, los extremos de las líneas indican los valores menor y mayor, y la línea interior de la caja muestra la mediana de los datos. En los diagramas psicrométricos se representa la interrelación de 3 variables: temperatura, humedad relativa y grado de humedad del aire, según la presión barométrica media, resultante de las mediciones realizadas in situ cada hora en el periodo de observación.

Los gráficos de curvas han permitido una aproximación al comportamiento de la cámara en función del clima local, y
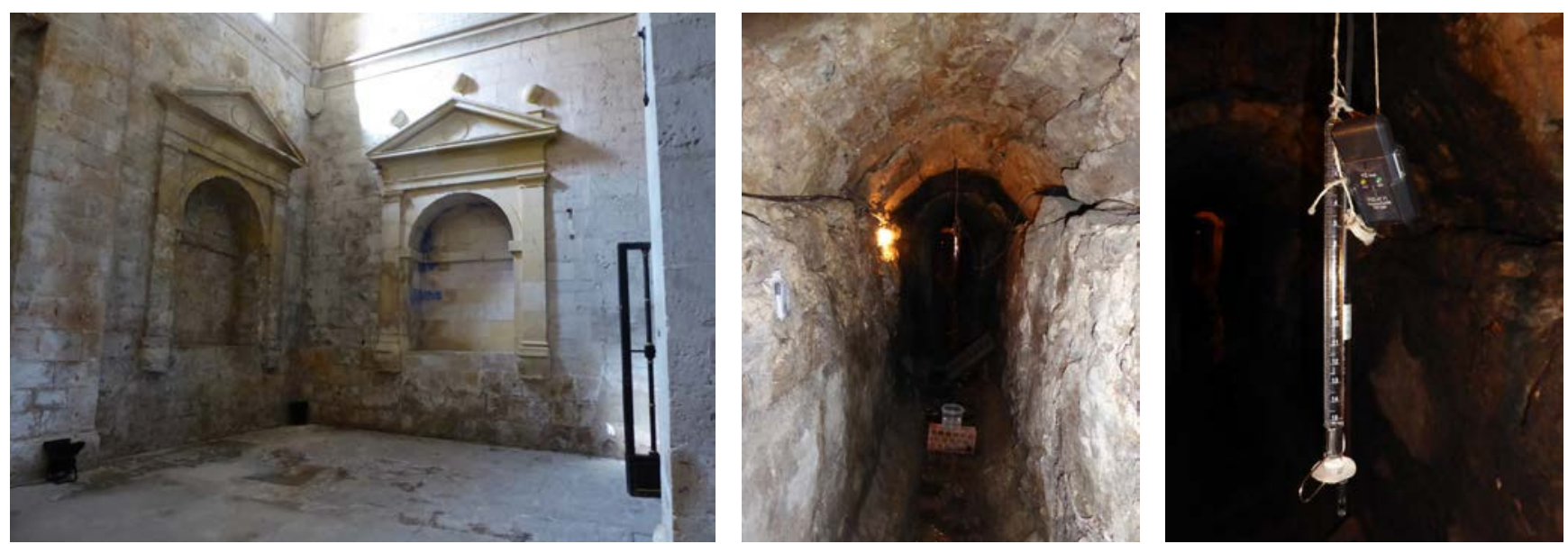

Figura 1. Monitorización de la cámara de drenaje-aireación de la iglesia de Santa Cruz la Real de Segovia, cámara piloto a) caracterización del ambiente de la iglesia y del muro mediante termohigrómetros (setiembre 2016); b y c) caracterización del muro y del ambiente de la cámara mediante termohigrómetros, anemómetro y evaporímetros (abril 2016). 
por tanto saber de la interrelación de la temperatura, la humedad y el flujo de aire del clima local con la tasa de evaporación del aire de la cámara (expresada en mm por unidad de tiempo). Los gráficos de caja y bigote han ayudado a conocer la fluctuación de los parámetros de temperatura y humedad y su incidencia en la evaporación de la cámara y el muro. Los diagramas psicrométricos han servido para apoyar el estudio de la evaporación de la cámara según el clima local y la evaporación del muro según las condiciones de la cámara.

\section{RESULTADOS Y DISCUSIÓN}

El tipo de cámara que se ha considerado más extremo es la cámara de drenaje ventilada, es decir, aquella cámara cuya función principal es drenar la escorrentía superficial del terreno. En este tipo de cámaras en ningún momento del año el aire deja de estar próximo a la saturación, aunque la cámara incorpore elementos que potencien la ventilación como pueden ser chimeneas verticales. Tal es el caso de la galería (histórica) de la iglesia de Santa Cruz la Real de Segovia (figuras 2 y 3 ).

En la cámara de Santa Cruz de Segovia, la tasa de evaporación difiere a lo largo del recorrido, siendo mayor en el punto medio del recorrido (entre chimeneas abiertas en contacto con el exterior, con una sección aproximada de $0,8 \times 1,3 \mathrm{~m}^{2}$ ) y no bajo la última chimenea en contacto con el clima local (la reja de registro tiene $0,8 \times 1,2 \mathrm{~m}^{2}$ y las salidas de las chimeneas $0,2 \times 0,5 \mathrm{~m}^{2}$ aproximadamente). De hecho, en la zona de mayor evaporación de todo el recorrido (mitad del recorrido) el mortero de cemento del muro de la iglesia presentaba sales en el periodo de invierno, siendo indicativo de que hay corrientes de aire que facilitan su afloración.

En el caso de Santa Cruz de Segovia, la cara interior del muro sur de la iglesia -la galería se encuentra adosada en su cara exterior- muestra huellas de humedad, que se pueden deber a distintas circunstancias: filtración de la conducción de pluviales, filtración del canal de la galería de drenaje que se sitúa en una cota inferior o filtración del terreno bajo la galería de drenaje. De hecho, el pavimento interior de la iglesia manifiesta manchas de humedad activas en el lado sur (más concretamente en las capillas laterales).

Si se evalúa la cámara ventilada que de manera temporal recibe aportes de agua, como pueden ser pluviales de cubierta o del entorno próximo, esta puede tener más o menos capacidad para evaporar los aportes de agua durante los periodos secos, en función del diseño de la cámara. Como ejemplo se tiene la cámara del atrio de la catedral de Zamora (12 y 13) (con una sección aproximada de 0,75 × 1,5 $\mathrm{m}^{2}$ ), en donde se filtran aguas de pluviales a través de las juntas del enlosado que cubre la cámara o a través de las rejillas de ventilación y registro de la misma (dispone de cuatro rejillas de $1 \times 1 \mathrm{~m}^{2}$ cada una). Este agua queda retenida en el suelo de la cámara, si este no tiene capacidad de absorberla, hasta que llegue un periodo seco en que se pueda evaporar (figura 4).

En el caso de la cámara del atrio de la catedral de Zamora, el clima seco es capaz de evaporar aportes de agua que se han producido en la cámara en periodos de precipitación (figura 5). En cualquier caso la tasa de evaporación en una cámara que recibe una cantidad limitada de precipitaciones y con capacidad de evaporación de la misma en periodo seco es mayor con respecto a la tasa de evaporación de una cámara de drenaje ventilada.

Esta cámara, a su vez, evapora a distinto ritmo según la orientación de cada tramo. El tramo con orientación este evapora más rápido que el tramo con orientación norte (figura 5c).

Si en la cámara las funciones están perfectamente delimitadas, se trata de una cámara propiamente ventilada, que a lo sumo recibe aportes naturales de subsuelo. En esta circunstancia se puede considerar la cámara de la iglesia de San Salvador de los Caballeros de Toro (Zamora) (14 y 15) (con una sección promedio de $\left.0,6 \times 0,85 \mathrm{~m}^{2}\right)$, con rejillas de ventilación continua en todo el recorrido, y que a su vez potencia el
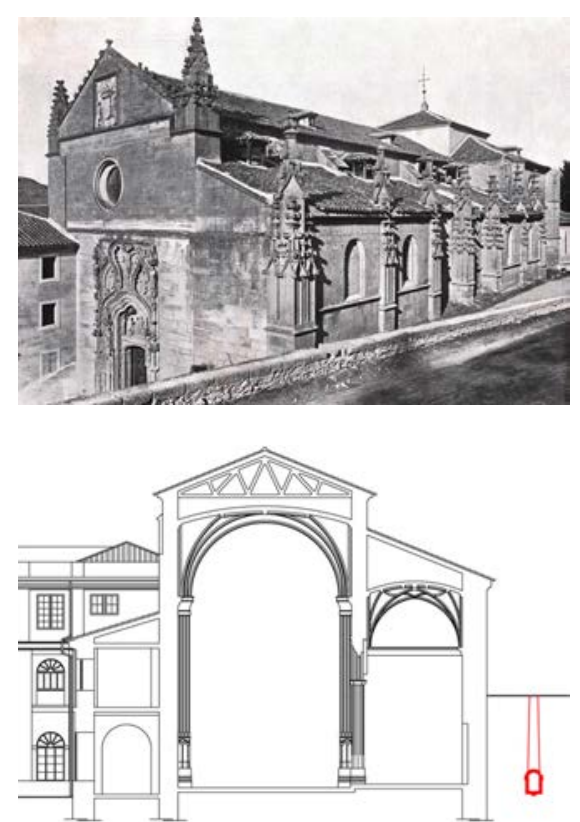

Figura 2. Cámara de drenaje-aireación de la iglesia de Santa Cruz la Real de Segovia: a) edificio (fotografía de J. Laurent, hacia 1920); b) sección transversal (planimetría base facilitada por Ismael Rodríguez); c) recorrido y ubicación de los registros, localización de los equipos y de las fotografías en planta y sección longitudinal (planimetría base facilitada por Ismael Rodríguez). 

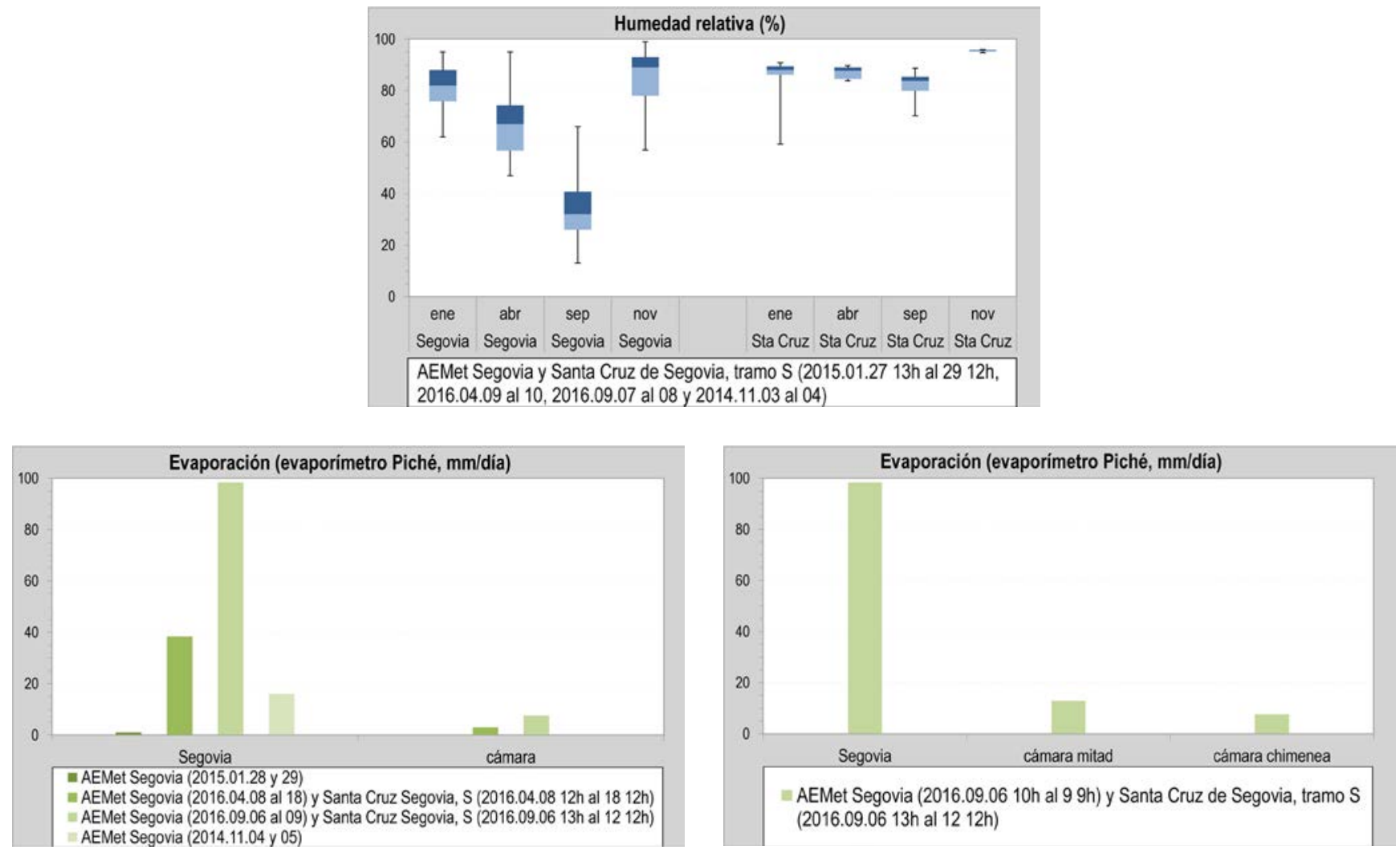

Figura 3. Comportamiento higrométrico y evaporación de la cámara de drenaje-aireación de la iglesia de Santa Cruz la Real de Segovia respecto al clima local: a) y b) humedad relativa y evaporación en las distintas estaciones meteorológicas; c) evaporación en dos puntos del recorrido en periodo seco.

tiro del aire en su tramo norte, al estar conectado este tramo al interior de la base de la torre de la iglesia (figura 6).

Se han documentado cámaras de pequeña sección, conformadas con muros de fábrica (sección de $0,4 \times 0,4 \mathrm{~m}^{2}$ ) o con prefabricados de hormigón, como mitades o cuartos de cilin- dro (de diámetro 1,2 m) que apoyan en muro y suelo a modo de cuarto de bóveda.

La sección de la cámara muchas veces está limitada por la cota de cimentación o por la presencia de restos arqueológicos a preservar.
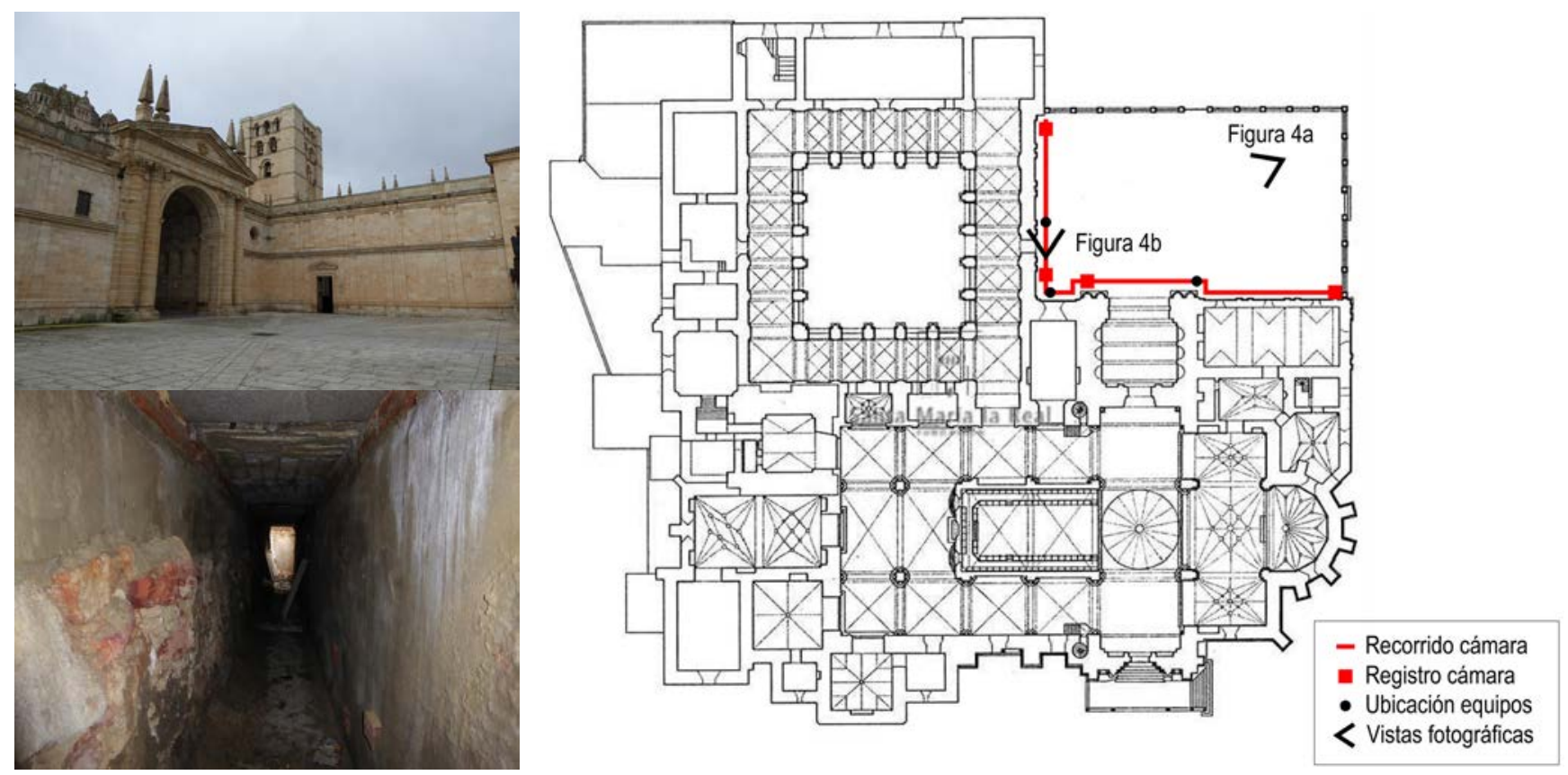

Figura 4. Cámara de aireación del atrio de la Catedral de Zamora: a) entorno (marzo 2016); b) vista del interior del tramo con orientación este, huellas de filtración de pluviales y suelo mojado (marzo 2016); c) recorrido y ubicación de los registros, localización de los equipos y de las fotografías en planta (planimetría base obtenida de <http://romanicodigital.com>, marzo 2016). 

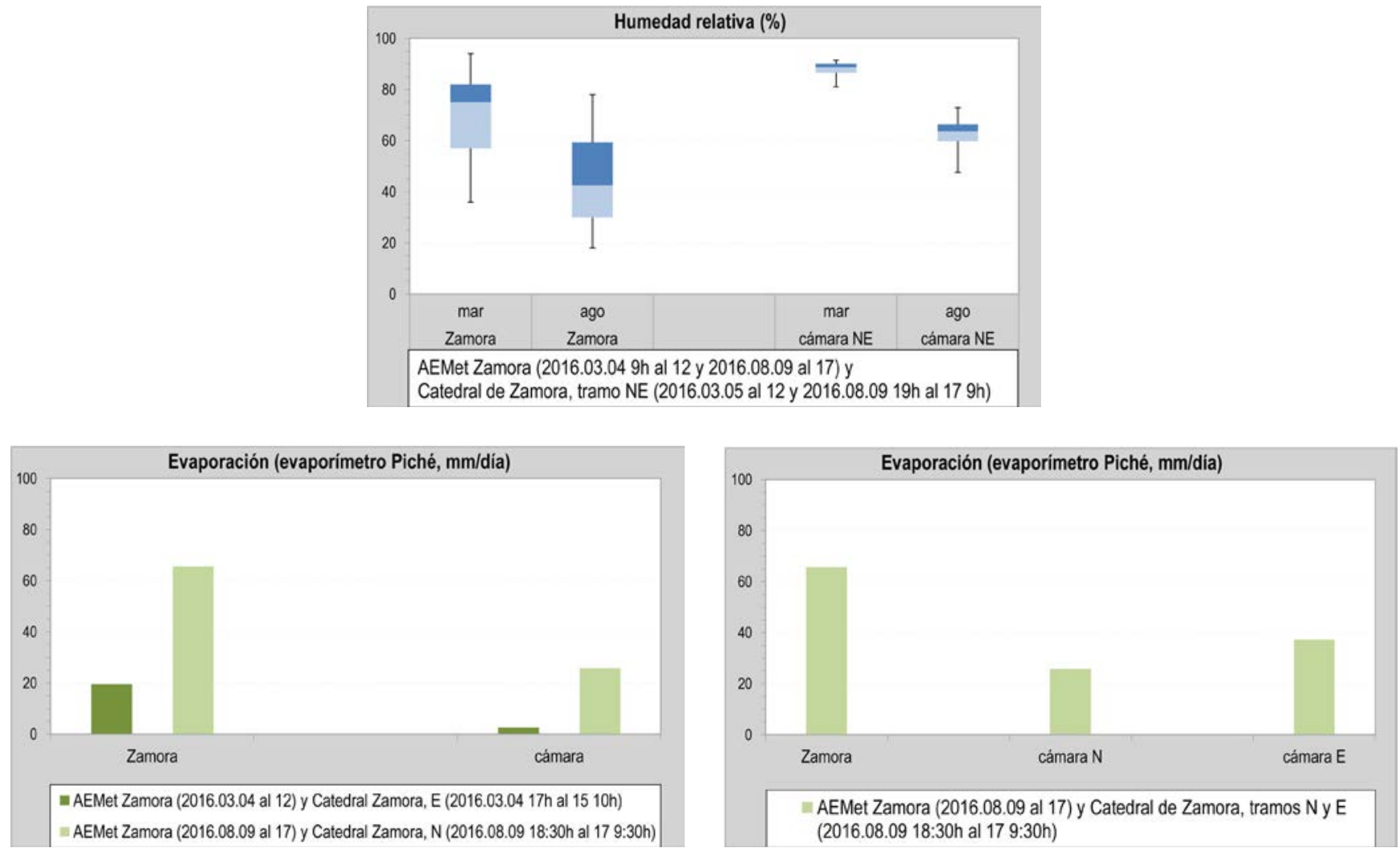

Figura 5. Comportamiento higrométrico y evaporación de la cámara de aireación del atrio de la Catedral de Zamora: a) y b) humedad relativa y evaporación en periodos lluvioso y seco; c) evaporación en dos puntos del recorrido en periodo seco.

En estas cámaras, normalmente las pluviales u otros aportes de agua quedan recogidos en un canal (de obra o prefabricado) o en un dren, colocados en paralelo a la cámara en su lado externo. A través del canal y del dren se pretenden recoger las pluviales de cubierta o del entorno próximo y los aportes de agua fortuitos, respectivamente. Debido a la reducida dimensión de las cámaras es especialmente importante la limpieza del canal, ya que la retención de agua por acumulación de suciedad no propicia la ventilación del muro, e incluso el agua podría llegar a rebasar el canal, que suele estar en contacto con la cámara. Un ejemplo de cámara de reducida dimensión se encuentra en la iglesia de San Lorenzo el Real de Toro (Zamora) (17) (figura 7).

Si se compara el comportamiento higrotérmico de cámaras de distinta sección, como pueden ser la de San Salvador y la de San Lorenzo de Toro -de sección menor que San Salvador-, se ve que la fluctuación de los parámetros es menor en el caso de San Lorenzo, en donde tanto la humedad relativa como el contenido de humedad son elevados incluso en verano, lo que limita la capacidad de evaporación no sólo de la cámara sino también del muro (figura 8).

Por tanto, se han encontrado casos (Santa Cruz de Segovia, catedral de Zamora y San Salvador de Toro) que intentan dar respuesta a los principales aportes de agua que puede recibir una cámara: escorrentía superficial del terreno, pluviales de cubierta y del entorno próximo y aportaciones del subsuelo. De cualquier modo, cuando en el clima local se tienen valores altos de humedad relativa la tasa de evaporación de la cámara estará muy limitada. Esta situación cambia si disminuye la humedad relativa del ambiente local, se restringen los aportes de agua y se potencia el tiro del aire (figura 9).
En las cámaras de ventilación pasiva se ha constatado que el comportamiento de los parámetros de temperatura y humedad relativa son contrarios: al aumentar la temperatura disminuye la humedad relativa y viceversa. No obstante, el grado de humedad tiene un comportamiento parejo a la temperatura, de tal modo que al subir la temperatura el grado de humedad del aire aumenta ya que tiene más capacidad parar retener vapor de agua. Con estos datos se observa que los parámetros de temperatura y humedad relativa del aire de la cámara tienen gran incidencia en la tasa de evaporación de la misma (figura 10).

Si se desciende al detalle, al comparar los datos diarios medidos en la cámara de San Salvador se aprecia que a mayor temperatura, menor contenido de humedad en el aire y por tanto mayor evaporación. Así, los parámetros de temperatura y humedad son los que más influyen en la evaporación de la cámara. Sin embargo, el flujo de aire incide en menor medida en la tasa de evaporación de la misma (figura 11).

Según el análisis realizado, atendiendo a una clasificación tipológica y en base a los casos medidos se puede hacer la siguiente valoración cualitativa de la eficacia de funcionamiento de las cámaras de aireación (figura 12).

La cámara de drenaje ventilada, es eficaz, si el canal de evacuación del agua presenta la debida pendiente, está convenientemente impermeabilizado, y no muestra obstrucciones de retención del agua. Sin embargo, la ventilación de la cámara y la evaporación del muro estarán muy mermadas.

En cualquier caso los tipos descritos a continuación pueden incorporar un drenaje en el trasdós del murete de contención 

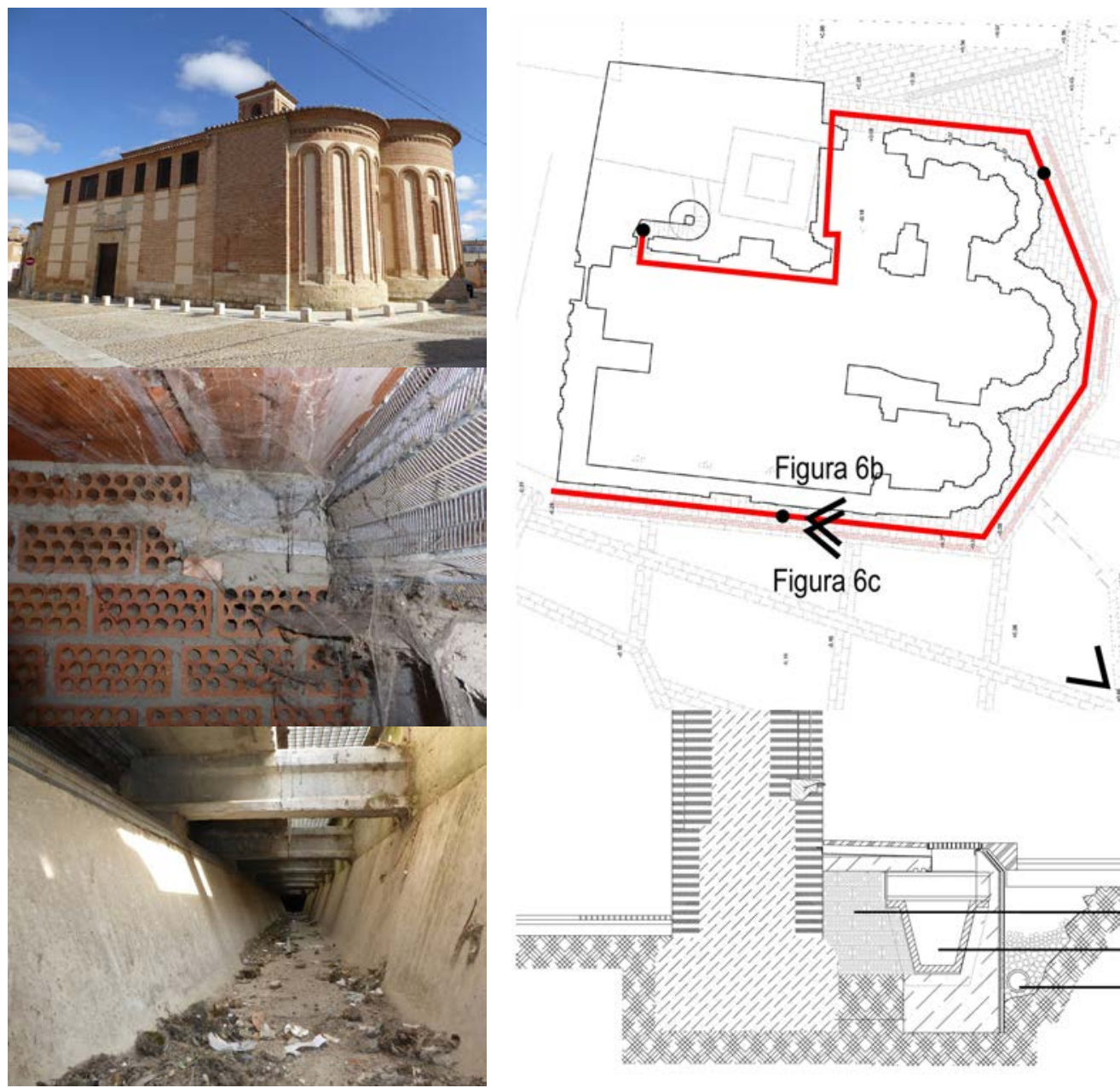

\section{- Recorrido cámara Registro cámara \\ - Ubicación equipos \\ $<$ Vistas fotográficas}

Figura 6. Cámara de aireación de la iglesia de San Salvador de los Caballeros en Toro (Zamora): a) edificio (julio 2016); b) vista del interior de la cámara (marzo 2016); c) vista del canal de pluviales (marzo 2016); d) recorrido y ubicación de los registros, localización de los equipos y de las fotografías en planta; y detalle de la sección (planimetría base facilitada por Pedro Lucas).
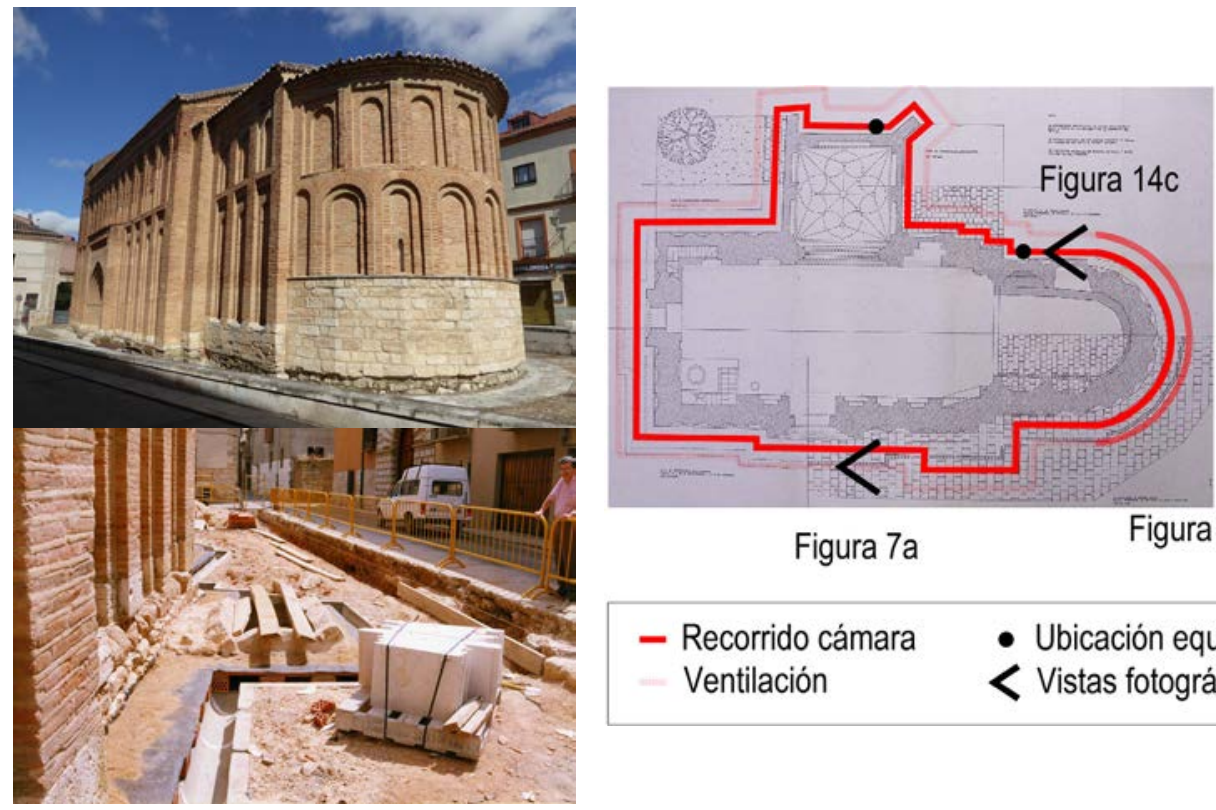

Figura $7 a$

Figura $7 \mathrm{~b} J$

\section{- Recorrido cámara Ventilación}

- Ubicación equipos $<$ Vistas fotográficas

Figura 7. Cámara de aireación de la iglesia de San Lorenzo el Real en Toro (Zamora): a) edificio (julio 2016); b) construcción del tramo sur (julio 1998, foto cedida por el Servicio Territorial de Cultura de Zamora); c) recorrido, localización de los equipos y de las fotografías en planta (planimetría base facilitada por Leocadio Peláez). 

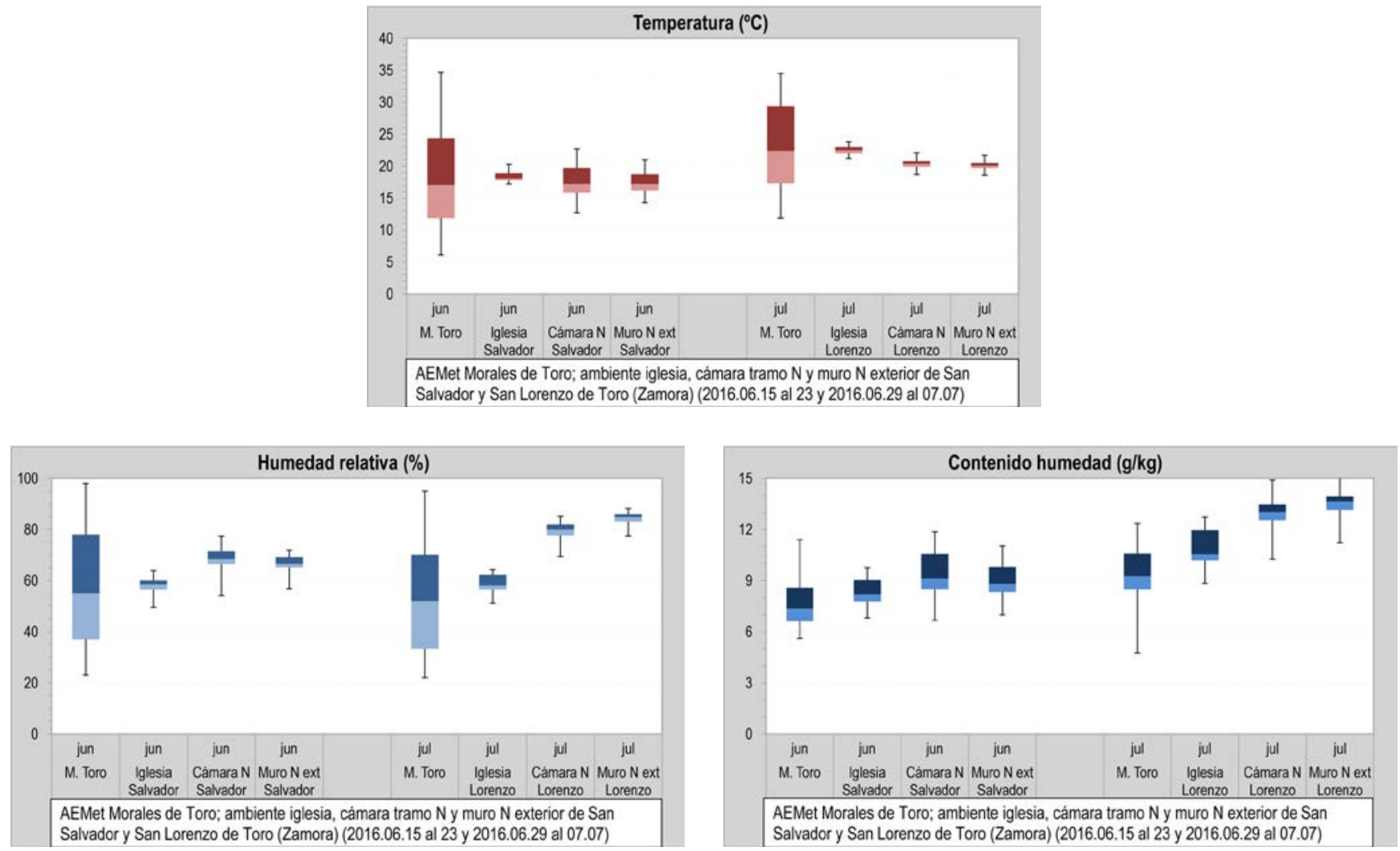

Figura 8. Comparativa del comportamiento higrotérmico entre el clima local, el microclima de la iglesia, el microclima de la cámara y el muro en contacto con la cámara de las iglesias de San Salvador y San Lorenzo de Toro (Zamora) en periodo seco (verano): a) temperatura; b) humedad relativa; c) contenido de humedad.
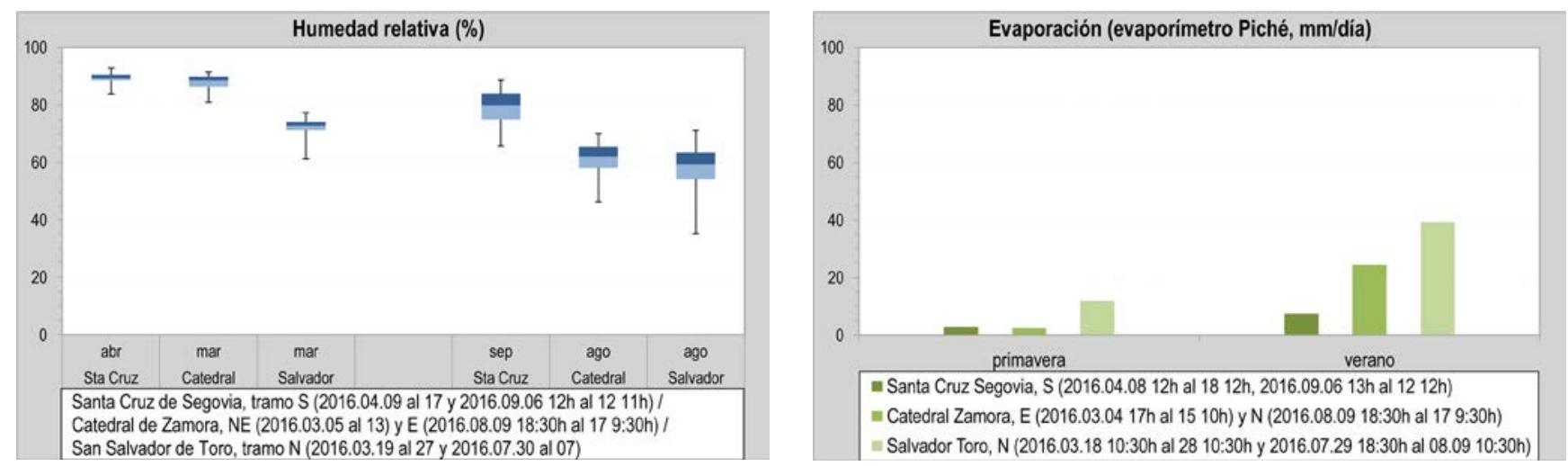

Figura 9. Comportamiento higrométrico y evaporación de distintas cámaras (Santa Cruz de Segovia, catedral de Zamora y San Salvador de Toro) en periodos de precipitación (primavera) y seco (verano): a) humedad relativa; b) evaporación.

para conducir la escorrentía superficial o los aportes fortuitos de las redes urbanas.

La cámara ventilada con aporte de agua del subsuelo, sin conexión al saneamiento, puede ser eficaz según el caudal de los aportes procedentes del subsuelo y si no hay filtraciones de escorrentía o de redes urbanas.

La cámara ventilada con aporte de precipitaciones, sin conexión al saneamiento, puede ser eficaz en la ventilación de la cámara y evaporación del muro en función del caudal de aportes recibidos en periodos de precipitación. En algunos de los casos estudiados se ha observado que en periodo de precipitaciones el agua entra en la cámara, cuestión no prevista en el diseño o no cuidada en la ejecución, de ahí que estas cámaras no sean eficaces al menos en periodo de precipitaciones.

La cámara ventilada con aporte de precipitaciones y conexión al saneamiento, sin funciones separadas, del mismo modo puede ser eficaz en la ventilación de la cámara y evaporación del muro según el caudal de aportes de agua recibidos en periodos de precipitación. La conexión al saneamiento ha de estar pensada para evitar el reflujo.

La cámara ventilada con aporte de precipitaciones y conexión al saneamiento, con funciones separadas, es eficaz según el volumen de la cámara. La conexión al saneamiento también ha de estar pensada para evitar el reflujo, ya que ante situaciones sobrevenidas la cámara se puede inundar. 

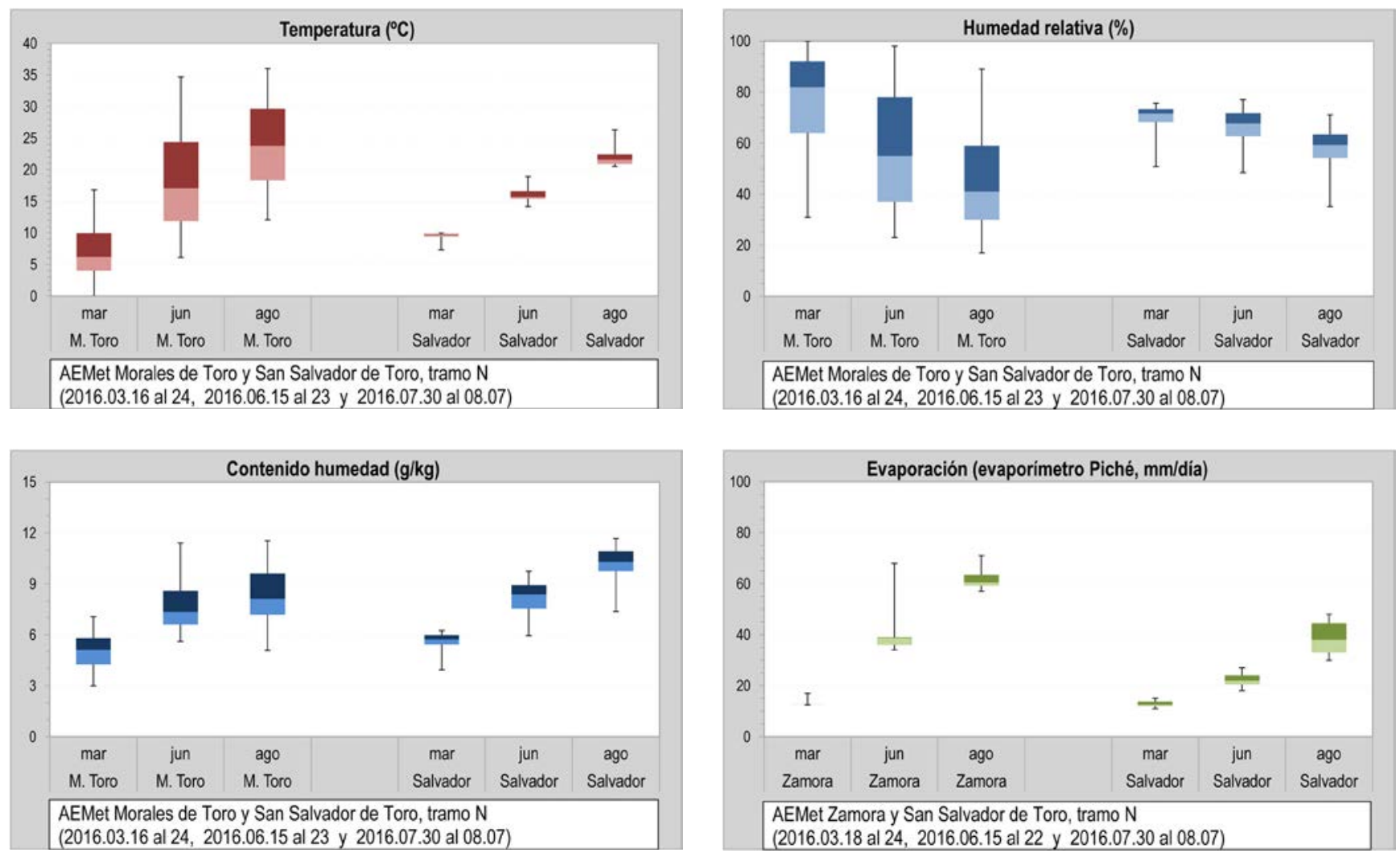

Figura 10. Comportamiento higrotérmico y evaporación de la cámara de aireación de la iglesia de San Salvador de los Caballeros en Toro (Zamora) en distintos periodos del año: a) temperatura; b) humedad relativa; c) grado de humedad; d) evaporación.
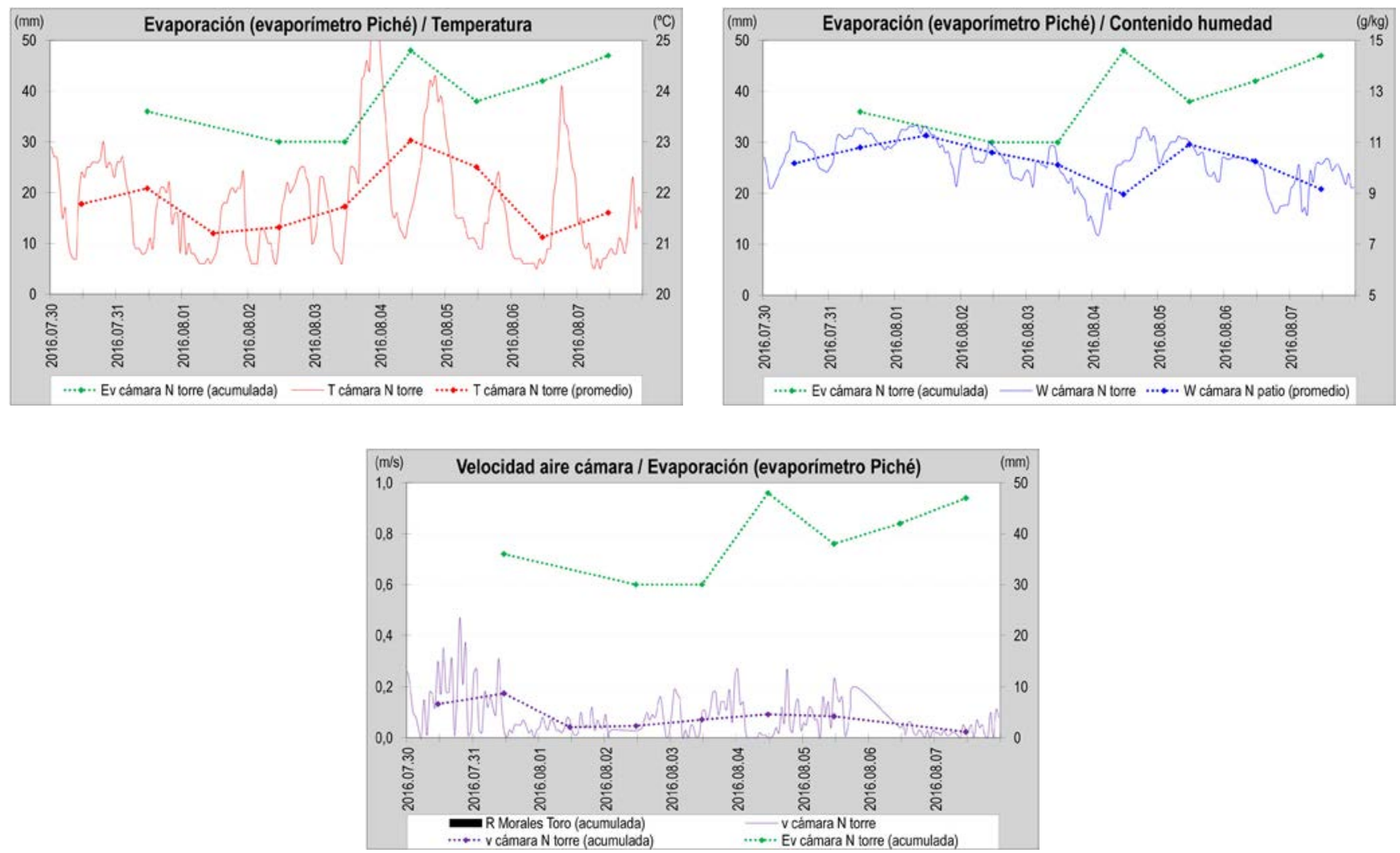

Figura 11. Influencia de distintas variables en la evaporación del tramo norte de la cámara de San Salvador de los Caballeros en Toro (Zamora) en periodo seco (verano): a) temperatura; b) contenido de humedad;

c) velocidad del aire. 


\begin{tabular}{|c|c|c|c|c|}
\hline$\underset{\substack{\text { Tipos } \\
\text { (Sistemas Pasivos) }}}{\text { Funciones }}$ & Conducción agua & $\begin{array}{l}\text { Ventilación } \\
\text { cámara/Evaporación } \\
\text { muro (cara en contacto } \\
\text { con la cámara) }\end{array}$ & Casos de estudio & Observaciones \\
\hline $\begin{array}{l}\text { Cámara de drenaje ventilada } \\
\text { (escorrentía del terreno). }\end{array}$ & $\begin{array}{l}\text { Eficaz, con las debidas } \\
\text { pendientes y sin } \\
\text { obstrucciones. }\end{array}$ & No eficaz. & Santa Cruz de Segovia. & $\begin{array}{l}\text { El resto de los tipos } \\
\text { descritos pueden } \\
\text { incorporar un drenaje } \\
\text { en el trasdós del } \\
\text { murete de contención. }\end{array}$ \\
\hline $\begin{array}{l}\text { Cámara ventilada con aporte de } \\
\text { agua del subsuelo (NF alejado de } \\
\text { cota cimentación), sin conexión al } \\
\text { saneamiento. }\end{array}$ & $\begin{array}{l}\text { Eficaz, según el caudal } \\
\text { de aportes recibidos. }\end{array}$ & $\begin{array}{l}\text { Eficaz, si no hay } \\
\text { filtraciones de escorrentía } \\
\text { o aportes fortuitos. }\end{array}$ & $\begin{array}{l}\text { Palacio Castrillo de } \\
\text { Toro (Zamora). }\end{array}$ & $\begin{array}{l}\text { Muchos aportes de } \\
\text { agua en el muro } \\
\text { son fortuitos (fugas } \\
\text { o roturas de redes } \\
\text { urbanas). } \\
\end{array}$ \\
\hline $\begin{array}{l}\text { Cámara ventilada con aporte de } \\
\text { precipitaciones, sin conexión al } \\
\text { saneamiento. }\end{array}$ & $\begin{array}{l}\text { No eficaz, el agua puede } \\
\text { quedar retenida hasta } \\
\text { que llegue un periodo } \\
\text { seco. }\end{array}$ & $\begin{array}{l}\text { Eficaz. Ineficaz en periodo } \\
\text { de precipitaciones, según } \\
\text { el caudal de aportes } \\
\text { recibidos. }\end{array}$ & $\begin{array}{l}\text { Catedral de Zamora. } \\
\text { San Pablo de } \\
\text { Valladolid. } \\
\text { Iglesia de Pinarejos } \\
\text { (Segovia). }\end{array}$ & $\begin{array}{l}\text { Los casos de San } \\
\text { Pablo y Pinarejos } \\
\text { reciben aportes de } \\
\text { precipitación que no } \\
\text { estaban previstos en } \\
\text { proyecto. }\end{array}$ \\
\hline $\begin{array}{l}\text { Cámara ventilada con aporte } \\
\text { de precipitaciones y conexión } \\
\text { al saneamiento, sin funciones } \\
\text { separadas. }\end{array}$ & $\begin{array}{l}\text { Eficaz siempre y cuando } \\
\text { se evite el reflujo. }\end{array}$ & $\begin{array}{l}\text { Eficaz. Ineficaz en periodo } \\
\text { de precipitaciones, según } \\
\text { el caudal de aportes } \\
\text { recibidos. }\end{array}$ & $\begin{array}{l}\text { Iglesia de Vall de } \\
\text { Almonacid (Castellón). }\end{array}$ & $\begin{array}{l}\text { No está claro si el } \\
\text { agua puede socavar } \\
\text { la cimentación con el } \\
\text { tiempo. }\end{array}$ \\
\hline $\begin{array}{l}\text { Cámara ventilada con aporte } \\
\text { de precipitaciones y conexión } \\
\text { al saneamiento, con funciones } \\
\text { separadas. }\end{array}$ & $\begin{array}{l}\text { Eficaz, siempre y } \\
\text { cuando se evite el } \\
\text { reflujo. }\end{array}$ & $\begin{array}{l}\text { Eficaz, según el volumen } \\
\text { de la cámara. }\end{array}$ & $\begin{array}{l}\text { San Salvador de Toro } \\
\text { (Zamora). } \\
\text { Iglesia de Villamor } \\
\text { (Zamora). } \\
\text { San Lorenzo de Toro } \\
\text { (Zamora). }\end{array}$ & $\begin{array}{l}\text { Ante situaciones } \\
\text { sobrevenidas la } \\
\text { cámara se puede } \\
\text { inundar, como fue el } \\
\text { caso de Villamor tras } \\
\text { el desbordamiento del } \\
\text { arroyo. }\end{array}$ \\
\hline
\end{tabular}

No eficaz

Poco eficaz

Eficaz

Muy eficaz

Figura 12. Tabla de valoración cualitativa de la eficacia de funcionamiento de las cámaras perimetrales de aireación en la base de los muros según tipos y casos de estudio. Código de color: Sistemas no eficaces en sombra roja, sistemas eficaces en sombra verde (de mayor a menor intensidad según grado de eficacia).

\section{CONCLUSIONES}

En una cámara de aireación el comportamiento de las distintas variables del aire depende de aspectos formales y funcionales.

1. Las cámaras de drenaje-aireación con aporte de agua continuo a lo largo de todo el año apenas tienen capacidad de evaporar la humedad de los muros, incluso en periodos secos. El canal, con la debida pendiente, se ha de mantener limpio para favorecer la evacuación del agua y se ha de impermeabilizar para impedir la filtración del mismo a los muros del edificio (figura 13a). La escala humana de la cámara facilitará esta labor.

2. Las cámaras de aireación que reciben aportes de agua en periodos de precipitación (pluviales del edificio y del entorno inmediato), podrán evaporar este agua en periodo seco, según el caudal retenido, las dimensiones de los huecos de ventilación y si el diseño propicia el movimiento del aire. En algunos casos se produce la entrada de agua de pluviales sin que estuviera previsto, bien por falta de limpieza en el entorno urbano próximo, por falta de mantenimiento de las redes urbanas colindantes o por un diseño que favorece la entrada de agua en el encuentro del forjado de la cámara con el muro del edificio (figura 13b). En estos casos ocurre que al no estar prevista la entrada de pluviales en la cámara no está pensada su evacuación, y el agua queda retenida en el suelo de la misma si no puede ser absorbida o si no puede ser evaporada, ya que el tama- ño de los huecos de ventilación y el diseño que propicia el movimiento del aire no son suficientes. En las cámaras de aireación que a su vez recogen pluviales del edificio y del entorno inmediato, no está claro qué incidencia pueden tener estas aguas en la cimentación del edificio, si la pueden socavar o hacer que se vaya desmoronando con el tiempo (figura 13c).

Según lo anterior:

3. Es primordial un diagnóstico preciso (objetivo, medido, calculado) que justifique la intervención para control de la humedad de capilaridad mediante cámaras de aireación (figura 14a).

4. Es fundamental adaptar el diseño de la cámara de aireación a las funciones que se quieren cubrir. Es conveniente redundar en determinados aspectos, para evitar la retención de agua en el entorno inmediato del edifico y su posible filtración en la cámara, para potenciar la evaporación del agua en la cámara o para impedir posibles reflujos de la red de saneamiento si el sistema está conectado a la red urbana (figura 14b), etc.

5. Es necesario el mantenimiento de los canales de evacuación de agua de la cámara y del entono inmediato (como limpiar la arena y suciedad o retirar los animales muertos que puedan dificultar la evacuación del agua o posibilitar el desbordamiento de los canales filtrándose el agua en la cámara de aireación si estas dos funciones están separadas), así como de los distintos elementos que po- 

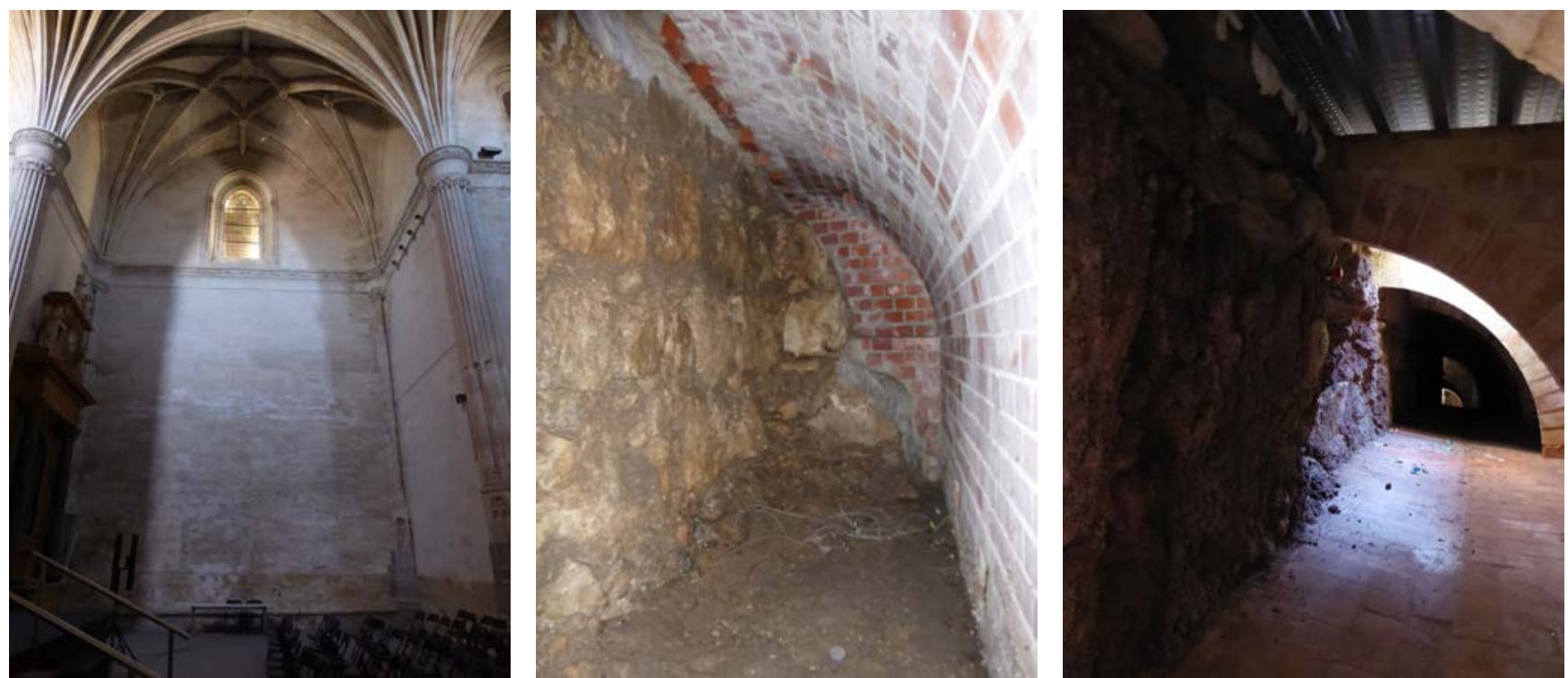

Figura 13. a) Iglesia de Santa Cruz la Real de Segovia, cara interior del muro sur (abril 2016); b) Cámara de aireación de la iglesia de San Pablo en Valladolid (febrero 2016); c) Cámara de aireación de la iglesia parroquial de Vall de Almonacid en Castellón (octubre 2015).
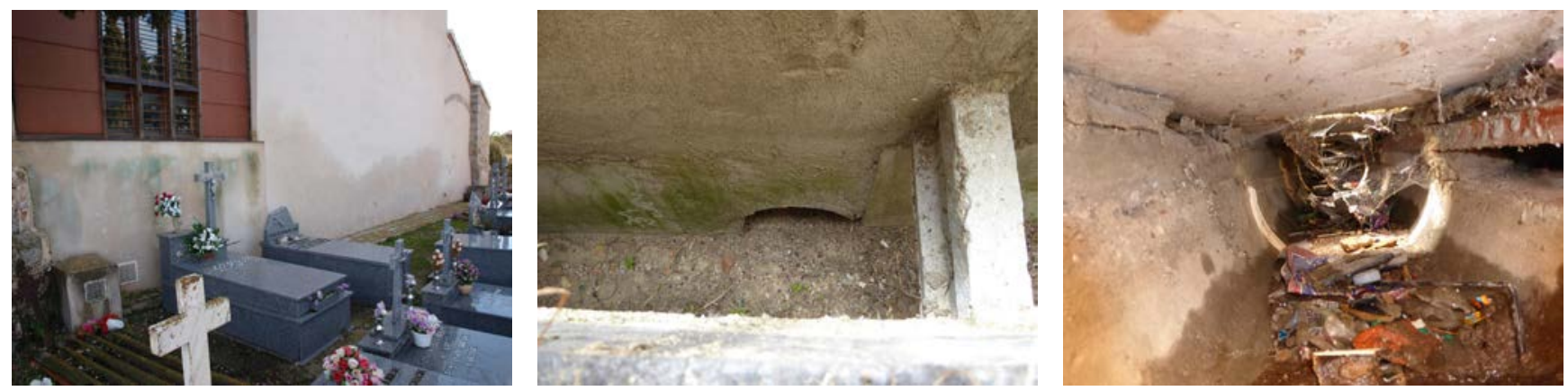

Figura 14. a) Muro oeste de la iglesia parroquial de Pinarejos (Segovia), manchas de humedad (febrero 2014, foto cedida por el Obispado de Segovia); b) Cámara de aireación de la iglesia parroquial de Villamor de los Escuderos (Zamora), tubo de evacuación de pluviales colmatado de arena (junio 2016); c) cámara de aireación de la iglesia de San Lorenzo de Toro (Zamora), canal de evacuación de pluviales lleno de suciedad (abril 2016).

sibilitan su funcionamiento (válvulas anti-retorno, etc.). En este sentido es interesante que el diseño facilite las labores de mantenimiento para evitar que la función de la cámara quede limitada o anulada, desencadenando otros riesgos para la conservación de los muros o del edificio. Por de pronto, en casi ninguna de las cámaras estudiadas se llevan a cabo tareas regulares de mantenimiento, normalmente estas tareas no están incorporadas a la rutina de mantenimiento del edificio (figura 14c). A esto se suma que en muchas ocasiones el diseño de la cámara no prevé esta circunstancia, de tal modo que no existen registros que permitan su mantenimiento.

\section{AGRADECIMIENTOS}

A todos los organismos, empresas y personas que de una manera u otra han propiciado el presente estudio: Diócesis de Zamora, Dirección General de Patrimonio Cultural de la Consejería de Cultura y Turismo de la Junta de Castilla y León, Servicio Territorial de Cultura de Zamora, IE Universidad en Segovia y Agencia Estatal de Meteorología; Empresa Rearasa y Construcciones Estejosan; Andrés Díez Herrero, José Carlos Sanz Belloso, Pedro Lucas del Teso, Manuela Andrés Temprano, José Navarro Talegón, Ángel Casaseca Beneítez y Leocadio Peláez Franco.

\section{REFERENCIAS}

(1) Massari, G. and Massari, I. (1993). Damp buildings, old and new. Rome: International Centre for the Study of the Preservation and the Restoration of Cultural Property.

(2) Salemi, A. (2000). Il Recupero e la conservazione delle fabbriche tradizionali: le patologie da umidità. Roma: Gangemi editore.

(3) López Collado, G. (1976). Las ruinas en construcciones antiguas: causas, consolidaciones y traslados. $2^{\mathrm{a}}$ edición. Madrid: Ministerio de Obras Públicas y Urbanismo.

(4) Ortega Andrade, F. (1994). Patología de la construcción: humedades en la edificación. Sevilla: Editan. 
(5) González Fraile, E. (2012). Galerías de ventilación para desecar las humedades en los zócalos de los monumentos. Papeles del Partal. Revista de Restauración Monumental, 5: 189-206.

(6) Freitas, V.P., Torres, M.I y Guimarães, A.S. (2008). Humidade ascensional. Faculdade de Engenharia de Universidade do Porto.

(7) Paricio, I. (1999). Vocabulario de arquitectura y construcción, p. 49. Barcelona: Bisagra.

(8) García Morales, S., Collado Gómez, A. y López González, L. (2012). Metodología de diagnóstico de humedades: la inspección higrotérmica con ayuda instrumental. En $4^{\circ}$ Congreso de Patología y Rehabilitación de Edificios. PATORREB 2012. Santiago de Compostela: Colexio Oficial de Aquitectos de Galicia.

(9) Kurnitski, J. (2001). Ground moisture evaporation in crawl spaces. Building and Environment, 36: 359-373, doi: https://doi.org/10.1016/So360-1323(00)oo013-5

(10) Sandrolini, F. (2006). An operative protocol for reliable measurements of moisture in porous materials of ancient buildings. Building and Environment, 41, pp. 1372-1380, doi: https://doi.org/10.1016/j.buildenv.2005.05.023

(11) García Gil, M.A. (1985). Proyecto de obras de reparación en la iglesia del convento de Santa Cruz de Segovia (Documento $\mathrm{n}^{0}$ 2). Segovia: Archivo de la Diputación Provincial de Segovia.

(12) Casaseca, A. (1989). Proyecto de restauración de la catedral de Zamora, $2^{\text {a }}$ fase. Zamora: Archivo de Casaseca Beneítez.

(13) Casaseca, A. (1991). Proyecto reformado de $2^{\text {a }}$ fase de restauración de cubiertas Santa Iglesia catedral de Zamora. Zamora: Archivo de Casaseca Beneítez.

(14) Lucas, P. (1992). Proyecto de acondicionamiento de la iglesia de San Salvador de los Caballeros de Toro (Zamora), como museo sacro. Valladolid: Archivo Central de la Consejería de Cultura y Turismo, Junta de Castilla y León.

(15) Lucas, P. (1994). Proyecto modificado de acondicionamiento N.1 de la iglesia de San Salvador de Toro (Zamora), como museo sacro. Valladolid: Archivo Central de la Consejería de Cultura y Turismo, Junta de Castilla y León.

(16) De Lera, M.A. y Peláez, L.J. (1997). Proyecto de saneamiento del ábside en la iglesia de San Lorenzo de Toro (Zamora). Valladolid: Archivo Central de la Consejería de Cultura y Turismo, Junta de Castilla y León. 